States of America; ${ }^{23}$ Facultad de Medicina Clínica Alemana - Universidad del Desarrollo, Rheumatology, Santiago, Chile; ${ }^{24}$ University Hospital Fundación Santa Fé de Bogotá and Universidad El Bosque, Rheumatology, Bogotá, Colombia; ${ }^{25}$ University of Alberta, Rheumatology, Alberta, Canada; ${ }^{26}$ Centre for Rheumatology and Department of Neuromuscular Diseases; University College of London, Rheumatology, London, United Kingdom; ${ }^{27}$ Amsterdam Rheumatology Center, AMC, Rheumatology, Amsterdam, Netherlands

Background: Patients with a diagnosis of Spondyloarthritis $(\mathrm{SpA})$ and Psoriatic Arthritis (PsA) may have predominant axial or peripheral symptoms, and the frequency and distribution of these symptoms may determine the clinical diagnosis by the rheumatologist ("clinical clusters"). Clustering analysis represents an unsupervised exploratory analysis which tries to identify homogeneous groups of cases ("statistical clusters") without prior information about the membership for any of the cases. Objectives: To identify "statistical clusters" of peripheral involvement according to the specific location of these symptoms in the whole spectrum of SpA and PsA (without prior information about the diagnosis of the patients), and to evaluate whether these "statistical clusters" are in agreement with the "clinical clusters".

Methods: Cross-sectional and multicentre study with 24 participating countries. Consecutive patients considered by their treating rheumatologist as suffering from either PsA, axial SpA (axSpA) or peripheral SpA ( $\mathrm{pSpA}$ ) were enrolled. Four different cluster analyses were conducted: the first one using information about the specific location from all the peripheral musculoskeletal manifestations (i.e., peripheral arthritis, enthesitis and dactylitis), and thereafter a cluster analysis for each peripheral manifestation individually. Multiple correspondence analyses and k-means clustering methods were used. Distribution of peripheral manifestations and clinical characteristics were compared across the different clusters. Results: 4465 patients were included in the analysis. Two clusters were found with regard to the location of all the peripheral manifestations (Fig. 1). Cluster 1 showed a low prevalence of peripheral manifestations in comparison with cluster 2; however, when peripheral involvement appeared in cluster 1 , this was mostly represented by arthritis of hip, knee and ankle, as well as enthesitis of the heel. Patients from cluster 1 showed a higher prevalence of males ( $63 \%$ vs $44 \%$ ), HLA-B27 positivity ( $69 \%$ vs $38 \%$ ) and axial involvement ( $80 \%$ vs $52 \%$ ), as well as more frequent diagnosis of axSpA $(66 \%$ vs $21 \%)$ and more frequently fulfilling the ASAS axSpA criteria $(69 \%$ vs. $41 \%)$. Patients from cluster 2 showed a higher prevalence of psoriasis $(63 \%$ vs $25 \%$ ), a more frequent diagnosis of PsA (61\% vs $19 \%)$, and they fulfilled more frequently the peripheral ASAS ( $26 \%$ vs $11 \%$ ) and the CASPAR criteria ( $57 \%$ vs $19 \%)$.

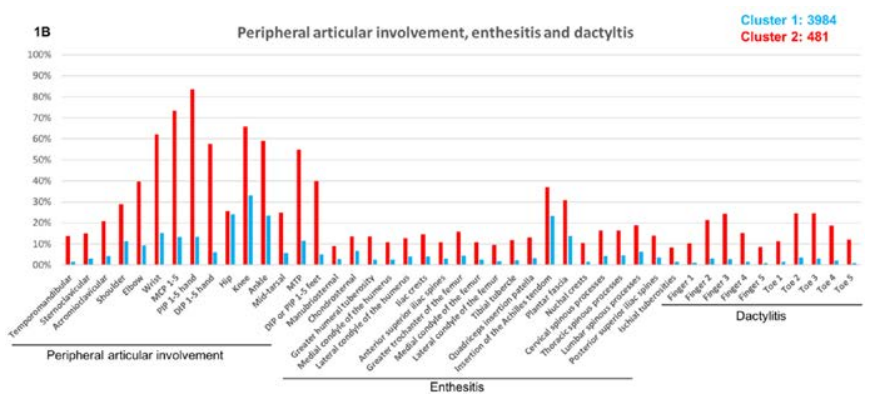

Figure 1. Distribution of the peripheral involvement across clusters

Three clusters were found with regard to the location of the peripheral arthritis. Clusters 2 and 3 showed a high prevalence of peripheral joint disease, although this was located more predominantly in the lower limbs in cluster 2 , and in the upper limbs in cluster 3. Cluster 1 showed a higher prevalence of males, HLA-B27 positivity, axial involvement, a lower presence of psoriasis, a more frequent diagnosis of axSpA and fulfilling the ASAS axSpA criteria in comparison with clusters 2 and 3 , respectively. Clusters 2 and 3 showed a higher prevalence of enthesitis and dactylitis in comparison with cluster 1, a more frequent diagnosis of PSA and fulfillment of the CASPAR criteria. Information about the location of enthesitis exhibited three groups: cluster 1 showed a very low prevalence of enthesitis, while cluster 2 and 3 showed a high prevalence of enthesitis, with a predominant involvement of axial enthesis in cluster 2 and peripheral enthesitis in cluster 3.

Finally, the analysis of dactylitis also exhibited three clusters that showed a very low prevalence of dactylitis, predominantly toes and predominantly fingers involvement, respectively.

Conclusion: These results suggest the presence of heterogeneous patterns of peripheral involvement in SpA and PsA patients without clearly defined groups, confirming the clear overlap of these peripheral manifestations across the different underlying diagnoses.

Acknowledgements: This study was conducted under the umbrella of ASAS with unrestricted grant of Abbvie, Pfizer, Lilly, Novartis, UCB, Janssen and Merck. Disclosure of Interests: None declared

DOI: 10.1136/annrheumdis-2021-eular.805

\section{OP0048 \\ DIAGNOSING AXIAL SPONDYLOARTHRITIS: ESTIMATION OF THE DISEASE PROBABILITY IN PATIENTS WITH A PRIORI DIFFERENT LIKELIHOODS OF THE DIAGNOSIS}

D. Poddubnyy ${ }^{1,2}$, F. Proft ${ }^{1}$, L. Spiller ${ }^{1}$, M. Protopopov ${ }^{1}$, V. Rios Rodriguez ${ }^{1}$, B. Muche ${ }^{1}$, J. Rademacher ${ }^{1}$, M. Torgutalp ${ }^{1}$, J. L. Vahldiek ${ }^{3}$, J. Sieper ${ }^{1}$,

I. Redeker ${ }^{2}{ }^{1}$ Charité - Universitätsmedizin Berlin, Division of Gastroenterology, Infectious Diseases and Rheumatology, Berlin, Germany; ${ }^{2}$ Deutsches RheumaForschungszentrum Berlin (DRFZ), ein Institut der Leibniz-Gemeinschaft, Epidemiology Unit, Berlin, Germany; ${ }^{3}$ Charité - Universitätsmedizin Berlin, Division of Radiology, Berlin, Germany

Background: The diagnostic approach in axial spondyloarthritis $(\mathrm{SpA})$ relies on a estimation of the post-test disease probability that is based on evaluation of positive and negative results of diagnostic tests in the context of the pre-test disease probability.

Objectives: To evaluate the diagnostic value of SpA parameters and their combination for the diagnosis of axial SpA in patients with an a priori different probability of the diagnosis.

Methods: A total of 361 patients with chronic back pain and suspicion of axial SpA (181 referred by primary care physicians or orthopaedists, 180 recruited via an online screening tool) received a structured rheumatologic examination as a part of the OptiRef study [1], which resulted into a diagnosis or exclusion of axial SpA. The prevalence of axial SpA indicating the pre-test probability was $40 \%$ in the physician-referred subgroup and $20 \%$ in the online screening subgroup. Sensitivities, specificities, and likelihood ratios (LRs) for SpA features were determined in both subgroups and the respective post-test probabilities of axial SpA were calculated. Results: The relative diagnostic value of single SpA features varied substantially between the groups with different referral pathways - see the online disease probability calculator http://www.axspa.de/calculator.html. It can be seen that the diagnostic values of the $S p A$ parameters vary substantially between the groups. For instance, HLA-B27 positivity increased the probability of the presence of axial SpA by $35 \%$ to $55 \%$ in online-screened patients and by $22 \%$ to $62 \%$ in physician-referred patients. Furthermore, the absence of HLA-B27 resulted in a sharp decrease in the probability of the presence of axial SpA in physician-referred patients (from $40 \%$ to $6 \%$ ). This decrease was less sharp in the online screening group (from 20\% to 10\%). Furthermore, combinations of parameters performed differently in the studied subgroups. Figure 1 illustrates that the observed differences in the diagnostic values of the SpA parameters in different subgroups were only clinically relevant in the presence of a low number of positive test results. For instance, combining IBP with anterior uveitis increased the post-test probability for axial SpA to $78 \%$ in the online screening group and to $87 \%$ in the physician-referred group, whereas using HLA-B27 positivity and active sacroilitis on MRI in combination with IBP resulted in a surge in the post-test probability of the presence of axial SpA to around $95 \%$ in both groups.

Figure 1. The relationship between the likelihood ratio product and the post-test probability of axial SpA in patients with different pre-test disease probability.

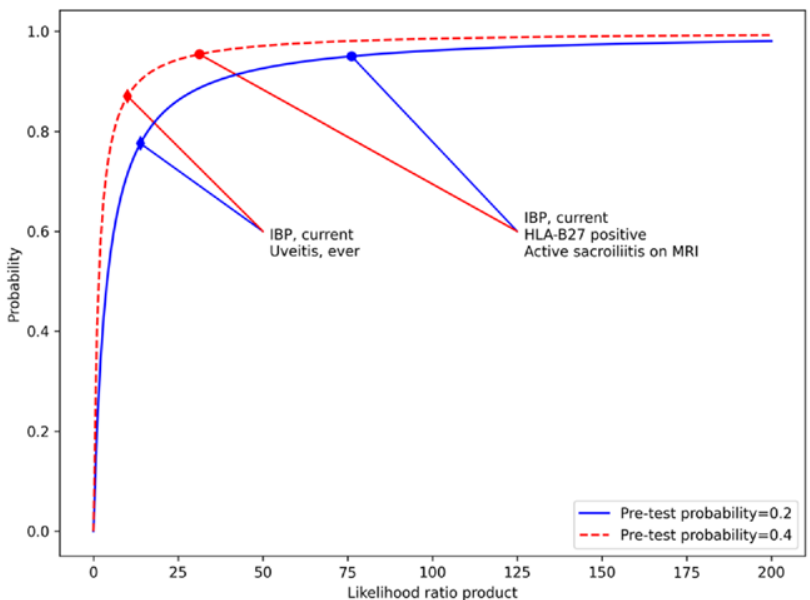

The relationship between the likelihood ratio product and the post-test probability of axial $\mathrm{SpA}$ is depicted for patients referred via an online screening tool (pre-test probability of axial SpA $=20 \%$ ) and in patients referred via a physician-based referral tool (pre-test probability of axial $\mathrm{SpA}=40 \%$ ).

IBP: inflammatory back pain; MRI: magnetic resonance imaging; SpA: spondyloarthritis. 
Conclusion: The diagnostic value of a single diagnostic test in the clinical practice is not fixed and a number of factors including the referral pathway can affect it. Fluctuation of the diagnostic values is especially relevant when the number of positive parameters is low (1-2).

\section{REFERENCES:}

[1] Proft F, et al. Semin Arthritis Rheum. 2020;50:1015-1021.

Acknowledgements: The OptiRef study was supported by a research grant from Novartis.

Disclosure of Interests: None declared

DOI: 10.1136/annrheumdis-2021-eular.3550

\section{OP0049 COMPARISON OF BASELINE DISEASE ACTIVITY AND PATIENT (PT)-REPORTED OUTCOMES (PROS) BETWEEN PTS WITH PSORIATIC ARTHRITIS AND AXIAL INVOLVEMENT (AXIAL PSA) AND AXIAL SPONDYLOARTHRITIS (AXIAL SPA) FROM THE CORRONA PSA/SPA REGISTRY}

P. J. Mease ${ }^{1}$, M. Marchese ${ }^{2}$, R. Mclean ${ }^{2}$, T. Blachley ${ }^{2}$, L. Anatale-Tardiff ${ }^{2}$, C. Saffore ${ }^{3}$, E. Lesser ${ }^{3}$, A. Ogdie ${ }^{4}{ }^{1}$ Swedish Medical Center/Providence St. Joseph Health and University of Washington, Seattle, United States of America; ${ }^{2}$ Corrona, LLC, Waltham, United States of America; ${ }^{3}$ AbbVie Inc., North Chicago, United States of America; ${ }^{4}$ University of Pennsylvania, Philadelphia, United States of America

Background: Although pts with axial PsA and axial SpA share some common clinical characteristics, there are also potential differences that may influence disease assessment and treatment response. Identifying differences between the two pt populations is important for assessment of disease characteristics and severity as well as informing treatment decisions. There has been little comparative characterization of these conditions in a US population.

Objectives: To compare characteristics of pts with axial PsA and axial SpA.

Methods: Pts $\geq 18$ years of age diagnosed with axial PsA or axial SpA at enrollment in the prospective, multicenter, observational Corrona PsA/SpA Registry between March 2013 and August 2020 were included. Enrollment visit demographics, clinical characteristics, treatment history, disease activity measures, and PROs were compared between disease groups. Continuous measures were reported using means and standard deviations; means for disease groups were compared using two-sample $t$ tests or Wilcoxon rank sum tests. Categorical measures were reported as frequencies and percentages; frequencies in disease groups were compared using chi-square or Fisher exact tests.

Results: A total of 1044 pts (470 with axial PsA and 574 with axial SpA) were identified (Table). Pts with axial PsA were older with a higher percentage being female vs pts with axial SpA. Time since symptom onset and diagnosis were shorter for pts with axial PsA vs axial SpA (12.0 vs 15.6 years $[P<0.001]$ and 6.8 vs 8.3 years $[P=0.01])$. Pts with axial PsA were less likely than pts with axial SpA to have current or historical uveitis (4\% vs $14 \%[P<0.001])$ or inflammatory bowel disease $(5 \%$ vs $10 \%[P=0.005])$. Prior biologic synthetic disease-modifying antirheumatic drug (bDMARD) and conventional synthetic DMARD use was more prevalent in the axial PsA vs axial SpA groups $(64 \%$ vs $52 \%[P<0.001] / 59 \%$ vs $32 \%[P<0.001])$, while mean dactylitis (measured by Dactylitis Count) and enthesitis (measured by Spondyloarthritis Research Consortium of Canada [SPARCC] Enthesitis Index) counts were higher ( 0.4 vs $0.1[P<0.001] / 1.7$ vs $1.2[P<0.001])$. Mean pt-reported pain and spinal pain were lower in pts with axial PsA vs axial SpA (49.4 vs $53.9[P=0.015] / 40.8$ vs $49.7[P<0.001])$ (Figure). The proportion of pts with morning stiffness along with mean fatigue and work impairment scores were similar between disease groups.

Table.

\begin{tabular}{|c|c|c|c|}
\hline $\begin{array}{l}\text { Baseline demographics and clinical } \\
\text { characteristics }\end{array}$ & $\begin{array}{l}\text { Axial PsA } \\
\mathrm{N}=470\end{array}$ & $\begin{array}{l}\text { Axial SpA } \\
\mathrm{N}=574\end{array}$ & $P$ value \\
\hline Age (years), mean $\pm S D$ & $51.6 \pm 13.2$ & $47.7 \pm 14.0$ & $<0.001$ \\
\hline Female, $n(\%)$ & $265(57)$ & $248(44)$ & $<0.001$ \\
\hline White, $\mathrm{n}(\%)$ & $428(94)$ & $507(91)$ & 0.089 \\
\hline Years since symptom onset, mean \pm SD & $12.0 \pm 11.6$ & $15.6 \pm 12.1$ & $<0.001$ \\
\hline Years since diagnosis, mean \pm SD & $6.8 \pm 9.0$ & $8.3 \pm 10.5$ & 0.010 \\
\hline HLA-B27 positive status, n/n (\%) & $52 / 189(28)$ & $214 / 295(73)$ & $<0.001$ \\
\hline Abnormal CRP, $n(\%)$ & $88(19)$ & $140(24)$ & 0.033 \\
\hline Uveitis, $n(\%)$ & $20(4)$ & $80(14)$ & $<0.001$ \\
\hline IBD, n (\%) & $25(5)$ & $59(10)$ & 0.005 \\
\hline Dactylitis count, mean $\pm \mathrm{SD}$ & $0.4 \pm 1.5$ & $0.1 \pm 0.7$ & $<0.001$ \\
\hline SPARCC enthesitis count, mean \pm SD & $1.7 \pm 2.9$ & $1.2 \pm 2.4$ & $<0.001$ \\
\hline Morning stiffness, $\mathrm{n}(\%)$ & 439 (95) & $537(96)$ & 0.923 \\
\hline BASDAI $(0-10)$, mean \pm SD & $4.8 \pm 2.5$ & $4.9 \pm 2.4$ & 0.463 \\
\hline BASDAI Q2 (0-10): spinal pain, mean \pm SD & $5.0 \pm 2.9$ & $5.7 \pm 2.9$ & $<0.001$ \\
\hline BASDAI Q3 (0-10): peripheral pain/swelling, mean \pm SD & $4.5 \pm 2.9$ & $4.0 \pm 3.1$ & 0.010 \\
\hline Modified BASDAI $(0-10)$, mean \pm SD & $5.0 \pm 2.5$ & $5.4 \pm 2.4$ & 0.013 \\
\hline Prior bDMARDs, $\mathrm{n}(\%)$ & $300(64)$ & $299(52)$ & $<0.001$ \\
\hline Prior csDMARDs, $\mathrm{n}(\%)$ & 275 (59) & $181(32)$ & $<0.001$ \\
\hline Prior prednisone use, $n(\%)$ & $54(12)$ & $73(13)$ & 0.611 \\
\hline Prior NSAID use, $n(\%)$ & $52(11)$ & $46(8)$ & 0.115 \\
\hline
\end{tabular}

Conclusion: Findings from this descriptive real-world analysis suggest there may be meaningful differences between pts with axial SpA and axial PsA but future studies are needed to better understand these differences.

Acknowledgements: Medical writing services provided by Alan Saltzman of Fishawack Facilitate Ltd, part of Fishawack Health, and funded by AbbVie.

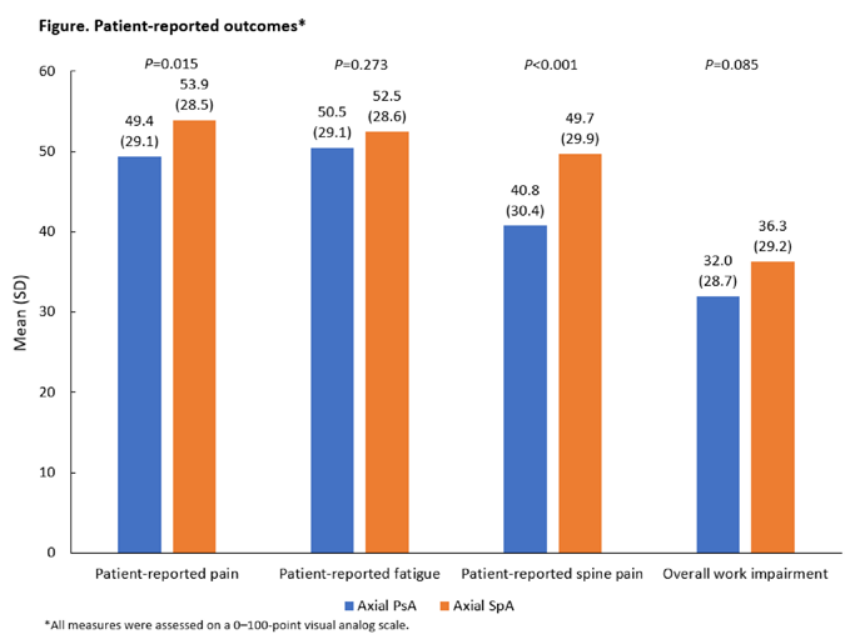

This study was sponsored by Corrona, LLC. Corrona has been supported through contracted subscriptions in the last 2 years by AbbVie, Amgen, Boehringer Ingelheim, Bristol Myers Squibb, Celgene, Crescendo, Eli Lilly and Company, Genentech, Gilead, GSK, Janssen, Merck, Momenta Pharmaceuticals, Novartis, Pfizer, Regeneron, Roche, Sun, UCB, and Valeant. The design, study conduct, and financial support for the study were provided by AbbVie. AbbVie participated in the interpretation of data, review, and approval of the abstract. No honoraria or payments were made for authorship.

Disclosure of Interests: Philip J Mease Speakers bureau: AbbVie, Amgen, Janssen, Lilly, Novartis, Pfizer, and UCB, Consultant of: AbbVie, Amgen, BMS Boehringer Ingelheim, Celgene, Galapagos, Gilead, GlaxoSmithKline, Janssen, Lilly, Novartis, Pfizer, Sun, and UCB, Grant/research support from: AbbVie, Amgen, BMS, Galapagos, Gilead, Janssen, Lilly, Novartis, Pfizer, Sun, and UCB, Maya Marchese Employee of: Corrona, Robert McLean Employee of: Corrona, Taylor Blachley Employee of: Corrona, Laura Anatale-Tardiff Employee of: Corrona, Christopher Saffore Shareholder of: AbbVie, Employee of: AbbVie, Elizabeth Lesser Shareholder of: AbbVie, Employee of: AbbVie, Alexis Ogdie Consultant of: Amgen, AbbVie, BMS, Celgene, Corrona, Gilead, Janssen, Lilly, Novartis, Pfizer, and UCB, Grant/research support from: National Institutes of Health/National Institute of Arthritis and Musculoskeletal and Skin Diseases, Rheumatology Research Foundation, National Psoriasis Foundation, Pfizer, and Novartis

DOI: 10.1136/annrheumdis-2021-eular.137

\section{OP0050 TWO-YEAR DIAGNOSTIC CONSISTENCY IN PATIENTS WITH CHRONIC BACK PAIN SUSPECTED OF AXIAL SPONDYLOARTHRITIS IN PROTOCOLISED FOLLOW-UP: DATA FROM THE SPONDYLOARTHRITIS CAUGHT EARLY COHORT}

A. Boel ${ }^{1}$, M. Van Lunteren ${ }^{1}$, K. M. Fagerli ${ }^{2}$, U. Lindström ${ }^{3}$, R. Ramonda ${ }^{4}$, M. G. H. Van de Sande ${ }^{5}$, F. A. Van Gaalen ${ }^{1}$, D. Van der Heijde ${ }^{1} .{ }^{1}$ Leiden University Medical Centre, Rheumatology, Leiden, Netherlands; ${ }^{2}$ Diakonhjemmet Hospital, Rheumatology, Oslo, Norway; ${ }^{3}$ University of Gothenburg, Rheumatology and Inflammation Research, Gothenburg, Sweden; ${ }^{4}$ University of Padova, Rheumatology Unit, Padova, Italy; ${ }^{5}$ Amsterdam University Medical Center, Clinical Immunology and Rheumatology, Amsterdam, Netherlands

Background: A diagnosis of (early) axial spondyloarthritis (axSpA) is based on pattern recognition, which can be challenging and may change over time.

Objectives: To investigate consistency of diagnosis over two years in patients with chronic back pain (<2 years symptoms) suspected of axSpA.

Methods: In the SPACE cohort, patients over 16 years of age referred to the rheumatology outpatient clinic with chronic back pain (CBP) ( $\geq 3$ months and $<2$ years) starting before the age of 45 , suspected of axSpA were included. Follow-up was performed only in patients with at least two $\mathrm{SpA}$ features or one $\mathrm{SpA}$ feature with a positive likelihood ratio $\geq 6.4^{1}$.

According to protocol, all $\mathrm{SpA}$ features as well as MRI and radiographs of the sacroiliac joints were performed at baseline and two years. Physicians were asked to report whether the diagnosis was axSpA or no axSpA at both timepoints, for which they had information available on all SpA features and locally 